\title{
European Scientific Governance in a Global Context: Resonances, Implications and Reflections
}

\author{
Maja Horst, Alan Irwin, Peter Healey and Rob Hagendijk'
}

\begin{abstract}
1 Introduction
The importance of public participation for effective policymaking is now widely endorsed. Public participation (or at least its advocacy) is considered essential to poverty reduction, social change in poor countries, city politics and local governance, development, building educational institutions and, importantly for this article, technological change and science-based innovation. Actors, institutions and organisations who agree on very little else at least do seem to agree about the centrality of engaging with and mobilising the public in support of better policies (even if they often fall out over the actual practice of participation).
\end{abstract}

In science and technology policy circles, the Danish model of 'consensus conferences' has been widely borrowed and, even more widely, discussed (e.g. Blok 2007). Dutch approaches to national debate and consensus formation (e.g. around energy policy) no longer appear quite so unique in the European context as they did in the 1980s. The UK has moved from its previous reliance on expert committees to some experimentation with public debate and engagement (notably, in the context of genetically modified foods but increasingly also in the area of nanotechnology) (Stilgoe et al. 2006). The European Commission has adopted a 'Science and Society action plan' (CEC 2002) in which issues of public support and engagement are given substantial prominence.

On the one hand, issues of science and technology policy (particularly genetic modification, stem cells and nanotechnology) have become central to political and institutional action, especially within Europe. Indeed, it could be argued that such matters have become a defining feature of the whole European project (as reflected for example in the
2000 Lisbon agenda aimed at making the European Union (EU) 'the most dynamic and competitive knowledge-based economy in the world'). On the other hand, there is a growing acceptance (fuelled partly by experience of previous controversies) that such matters cannot be tackled without public engagement and support (or at least legitimation and acceptance). In this situation, it is perhaps tempting to talk of a new 'European' paradigm for scientific governance in which science and society work together and innovative forms of social partnership are being created. In this article, drawing on the results of the STAGE project (Science, Technology and Governance in Europe), we will specifically examine the evidence for such a new European governance style. ${ }^{1}$

As an EU-funded thematic network, STAGE drew upon collaboration between researchers across Western Europe in 2001-5. It did not set out to 'sample' European experience systematically but rather to explore a range of accessible and potentially interesting examples of 'European' scientific governance in action. It was based on 26 case studies and country syntheses across eight European nations, as illustrated in Table 1 (full information and access to all the case studies is available at: www.stage-research.net). Our cases suggest a diversity of European governance practices - but also certain thematic links and common debates (Hagendijk and Irwin 2006). As we will show, signs of convergence can be identified, particularly around a widespread interest (at least on the rhetorical level) in deliberative forms of governance, but there continues to be a wide diversity of approaches and configurations.

In drawing attention to signs of convergence and a trend towards endorsing participation, it is also 
important to maintain a critical perspective on the kinds of change that have taken place. As a number of colleagues within the STAGE network have observed, there is indeed a danger that this shift is taking place largely at the level of rhetoric - of 'talk about talk' (Hagendijk 2004; Horst 2003; Irwin 2001). Equally, in an entity of the scale, complexity and diversity of the $E U$, it is unlikely that any pattern of change will be uniform or one-directional (Jasanoff 2005). As previous research in the EU has suggested (Rothstein et al. 1999), standardisation and diversity often accompany one another so that attempts to impose a common European pattern can actually accentuate matters of local identity and difference.

This article then focuses on specifically European treatments of public engagement with science and technology. However, there are strong thematic and practical concerns that are common to many international contexts, both within and outside Europe. Thus, a shared concern has been expressed as to whether public mobilisation is just another form of political marketing or a genuine attempt to introduce 'deeper' forms of democracy: is it legitimation or engagement, frothy rhetoric or paradigm shift? Our argument in this article is that such questions cannot be answered in general, but only with particular regard to particular cases and contexts. This approach is broadly in line with John Gaventa's view that democracy-building is an ongoing process of struggle and contestation, rather than the adoption of a standard recipe or institutional blueprint (Gaventa 2006).

The question of whether there is a European model of scientific governance and whether this can be of use to policymaking in other parts of the world unavoidably also touches upon well-entrenched distinctions between the 'North' and the 'South', between centre and periphery and between 'developed' and 'underdeveloped' countries. As Payne (2005) and others have argued, such distinctions have always been simplifications. The emergence of India, China and Brazil and other countries and regions as new 'knowledge economies' in a globalising world, have made such categorical distinctions even more problematic. Rich countries and regions like the USA and the EU are themselves in transformation and feel themselves under competitive threat. Development is now everywhere, as the editorial in the first issue of the journal Progress in Development Studies commented. In our view, this (admittedly partial) deconstruction of older categories makes the potential lessons that can be drawn from the European experience for public engagement in other parts of the world even more interesting and relevant. How should we conceptualise 'European' experience - especially given its inherent heterogeneity and diversity but also cross-fertilisation and shifting boundaries? What resonances, implications and reflections does this suggest with regard to science and democracy in other parts of the world?

Our general argument in what follows is not that a new paradigm of engagement has swept across Europe, pushing aside the old emphasis on innovation and economic competition. Although interesting social experiments in engagement have taken place, it is not plausible to suggest that these have replaced more familiar modes of governance and institutional action. In any case, significant debate still surrounds the form and effectiveness of such experiments.

What we do argue instead is that Western Europe represents a particularly important site for the study of scientific governance. As the following typology of governance will convey, it is oversimplistic to portray European scientific governance as caught in a battle between two models of governance (e.g. the neoclassical vs. the deliberative). Instead, we present a situation where a number of governance modes are in loose (often implicit and unacknowledged) coexistence and (sometimes) competition. What makes Europe noteworthy in a global context, is an emergent European culture of scientific governance in which new issues of 'science, society and innovation' have become mainstream. In this article, we explore the contemporary scientific and governance culture in Europe and look for lessons to draw for analysis and action. In so doing, our working hypothesis is that the European experience - while not directly applicable elsewhere - does represent a significant testing ground for notions of science, governance and democracy. As Gaventa (2006: 22) expressed: 'Taking a constructionist approach to democracy means that strategies for deepening democracy will look differently in different places, but at the same time we need more systematic knowledge ... of what the promising strategies might be across a much wider range of political and social conditions'. 


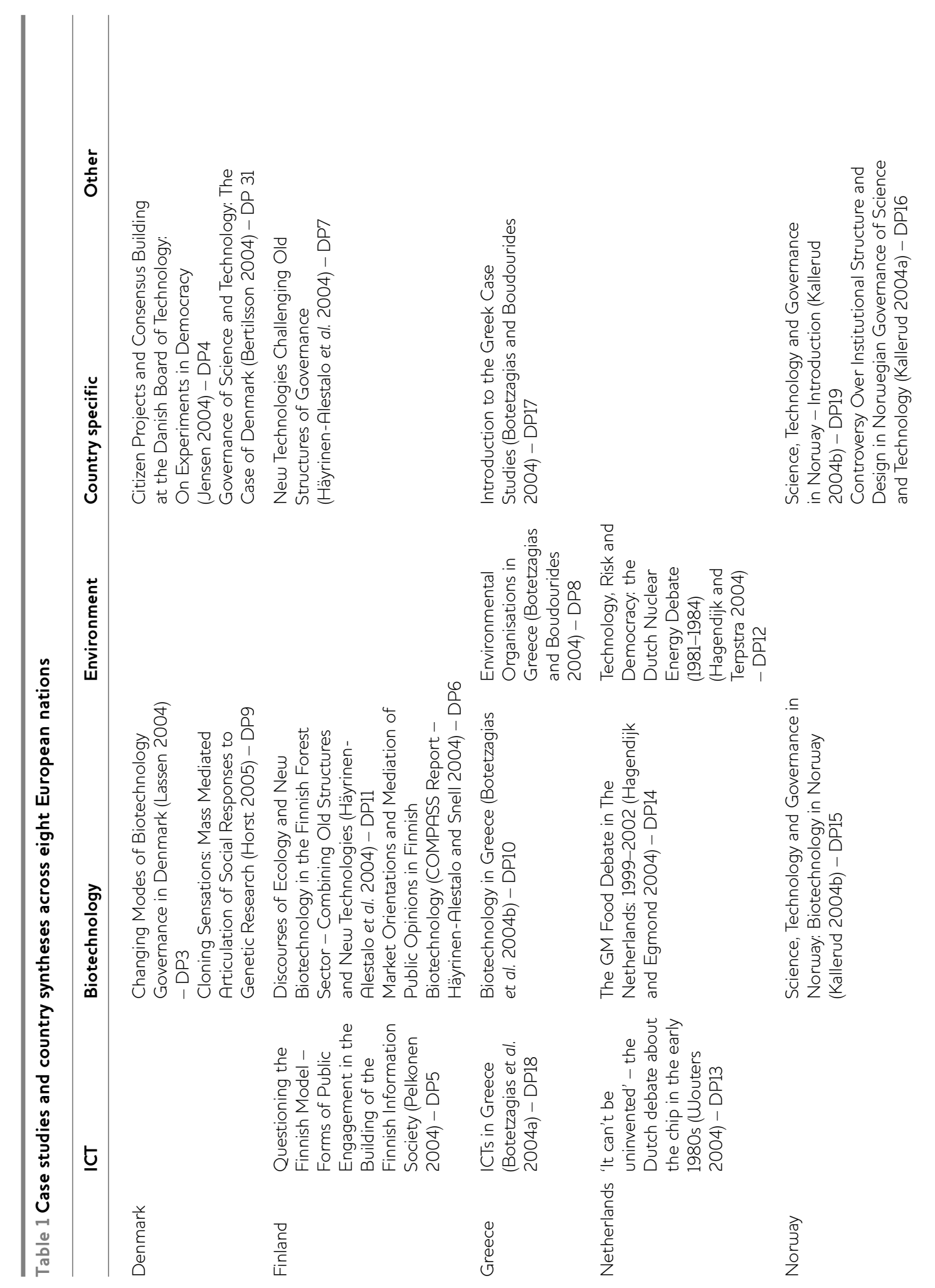

8 Horst et al. European Scientific Governance in a Global Context: Resonances, Implications and Reflections 


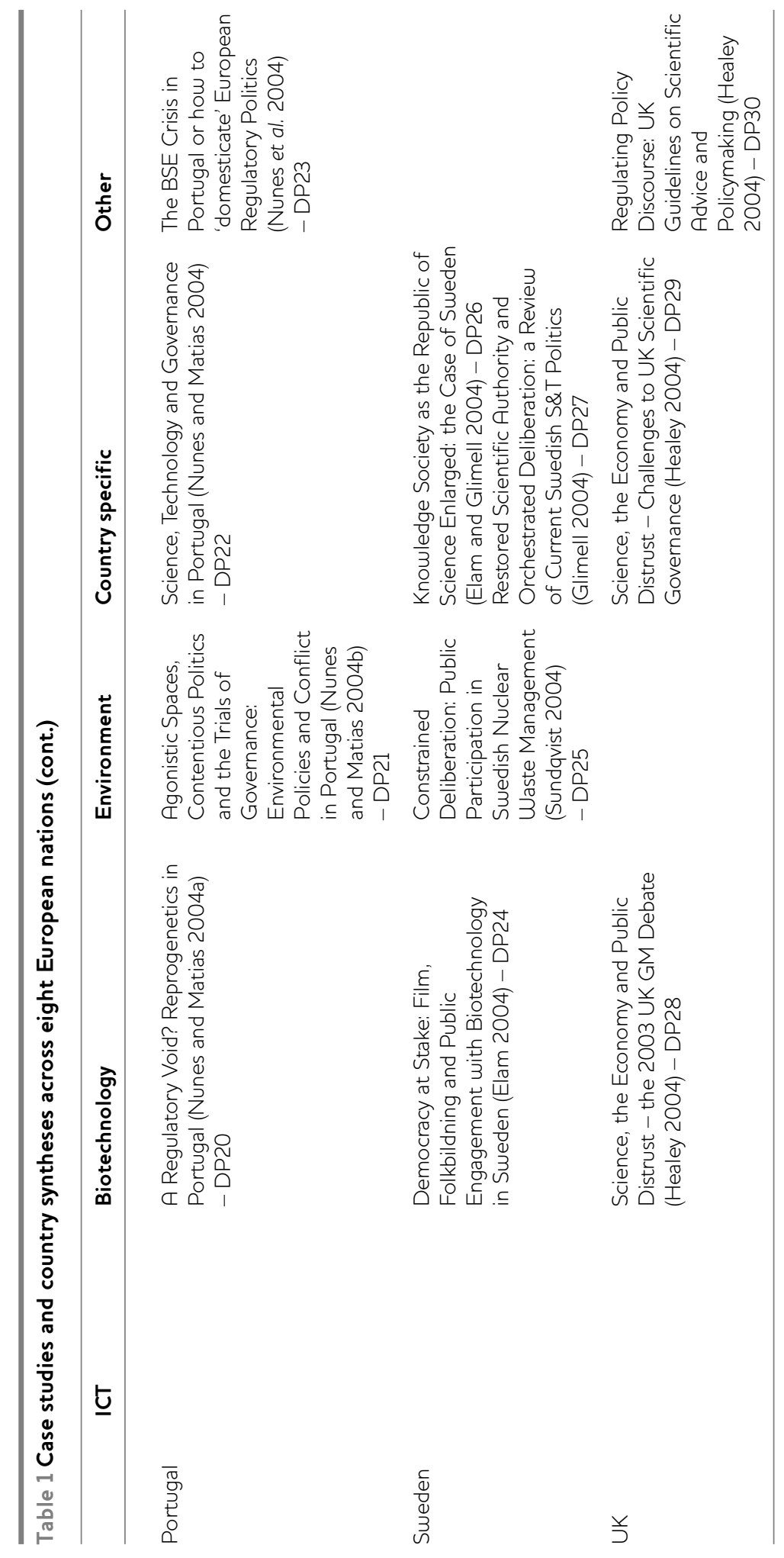

IDS Bulletin Volume 38 Number 5 November 2007 


\section{A typology of governance}

After preliminary discussions in the STAGE project (Elam and Bertilsson 2003) we considered it important to move beyond simple bi-modal presentations of governance styles. Too much discussion about public and deliberative engagement with science and technology has taken the form of either/or presentation: typically, either an emphasis on innovation and competition or a concern with democracy and engagement (alternatively, either public engagement is a serious endeavour or it is a legitimatory sham). Furthermore, early explorations of the cases and the national contexts demonstrated that it would not be feasible (or productive) to typify national polities in a fixed classification scheme. Such classifications tend to present national contexts as a rigid backdrop against which individual cases play out. Instead, a process-oriented taxonomy was developed through which different forms of governance and forms of public engagement could be characterised and related to one another (Hagendijk and Kallerud 2003).

One important aspect of this typology is to allow comparisons of the roles assigned to 'public' groups in various instances and cases of public engagement. Is 'the public' being constructed as active or passive; as consumers or as citizens; as homogeneous and stable or as fractured and dynamic? Each mode posited in the typology 'performs' the relationship between scientific/technological innovation and wider society in a distinctive manner. Yet, no country is assumed to fit straightforwardly into any single category and all actually combine a mix of these elements in addressing specific situations (Horst 2005). Equally, the categories are not intended to be watertight. Considerable overlaps can be identified, for example, between the corporatist and deliberative (or educational and market) approaches.

The heuristic typology was employed to analyse similarities and differences in various national developments within Europe (see Hagendijk et al. 2005). The following is a brief integrated summary of the typology and the findings:

- Discretionary. In discretionary governance, policymaking takes place with virtually no explicit interaction with 'the public'. On a general level, science governance in Portugal and Greece can be seen to exemplify this discretionary mode in the sense that governance is presented primarily as a matter for government. Government is portrayed as serving universal goals of progress, welfare and growth. Equally, the public interest is considered easy to define and enact. Within this mode, there is no sustained effort to incorporate the views of various publics in policy processes, let alone to develop a culture of scientific citizenship.

- Corporatist. Within corporatist governance, differences of interest between stakeholders are recognised as inputs to processes of negotiation in which workable compromises are sought. The processes of negotiation take place within a closed or highly regulated space, so the decisive feature is the question of admission and recognition of legitimate stakeholders. Generally, the Scandinavian countries can be taken to exemplify this mode of governance. In Sweden, the creation of a knowledge society as a necessary prerequisite for a well-functioning national innovation system has been seen as a commonly shared goal. Norway and Denmark have developed an inclusive corporatist mode of governance where various oppositional voices are sought to be included as stakeholders in the processes of negotiation.

- Educational. Educational modes of governance assume that conflicts or tensions regarding science and technology policy are founded on a lack of knowledge on the part of the public. Hence it is necessary to educate the public through dissemination of scientific (expert) knowledge in order to create an informed public of scientific citizens that understand the experts' assessment of the problems and possibilities of science. A notable example of this educational mode has been the effort to create a pervasive scientific culture in Portugal through a national agency. The efforts in Finland and Sweden to increase the public understanding of science as a necessary component of building a knowledge society can also be seen as exemplifying this educational mode of governance.

- Market. Market governance is based on the notion that science and technology can be governed through the economic mechanisms of demand and supply. In this mode, the public participates as customers and consumers in a market when they make decisions about purchasing a product. Compared with countries 
outside the EU (notably the USA), European traditions of governance may be less explicitly market oriented (although science and technology policy discussion in the UK about the need for 'confident consumers' fits this model well). However, there are signs that economic liberalisation and deregulation are increasingly leading to a market mode of governance (as for example, in Finland). This is exemplified also by the persistent suggestion that GMO labelling is the best means of letting consumers choose for themselves rather than relying on complex regulatory structures.

- Agonistic. Agonistic governance takes place under conditions of confrontation and adversity, when decisions have to be made in a political context where positions are strongly opposed. The political democracies of Europe are not primarily characterised by agonistic forms of governance. It seems, however, that certain policy processes regarding science and technology evolve in ways which can lead to a form of agonistic stalemate. Governance of nuclear waste in the UK, for instance, is an example where policy decisions are being made (or attempted) in the face of heated public opposition. Agonistic processes suggest a loss of control by the state as a variety of stakeholders struggle for authority and influence.

- Deliberative. Deliberative governance rests on the ideal that governance of science can be based on strong public support deriving from a continuous public debate of, and engagement with, science. In this mode, members of the public do not partake as consumers of science, but as scientific citizens who take on the perspective of the common good. This concept of public deliberation cannot be seen as a complete description of policy formation in any of the European countries. Nevertheless, it seems to be an ideal, which - as we have already noted - is rather important in the constitution of science governance, and various participatory exercises have been moulded around this aspiration. In particular, the consensus conferences organised by the Danish Board of Technology have been influential in this context.

As this brief presentation of the STAGE-typology and its application in our project suggests, scientific governance in Europe cannot be interpreted as a simple pattern of convergence or a linear, unidirectional development. The case studies within STAGE demonstrate that none of the examined European countries can be characterised by only one of these modes of governance. Rather, each country can best be described as a unique mix of several of these modes. For example, the UK manifests just about every mode - although corporatism has largely been out of fashion there since the 1970s.

Furthermore, it seems that the different national styles of governance are not stable, but rather in periodic transition (Sweden may be moving forcefully towards an educational mode, see Elam and Glimell 2004). Although there seem to be patterns of mutual influence, it is clear that different countries follow different trajectories, individually shaped by local, national cultures.

Our wider argument is that it is specifically this coexistence of modes that represents the European framework (or style) of scientific governance. As this article will go on to discuss, the juxtaposition and 'churning' of modes offers a unique opportunity to consider the future possibilities for scientific governance. In that sense, Europe represents a distinctive social and institutional laboratory. We are not therefore offering a unitary paradigm of scientific governance in Europe but instead a more complex and internationally distinctive - pattern of diversity, coexistence and contradiction/complementarity. It follows that merely criticising individual nations for being 'insufficiently' committed to one mode or another (e.g. for failing to live up to deliberative ideals) may be of limited intellectual and practical benefit. Rather, there is a general need for greater analytical clarity - and policy reflection with respect to the ways in which (and when) modes of governance are combined. The current political tendency is to make separate 'modal appeals' simultaneously: as when institutional rhetoric (e.g. in government reports and major political speeches) shifts - at times, very abruptly - between public engagement and greater international competitiveness without pausing to consider their possible connection or tension (Irwin 2006)

The STAGE-typology should therefore not be seen as a meta-framework for judging (or comparing) national styles of science governance in order to assess whether they comply with a single European paradigm. Instead, the typology is employed as a heuristic model, which makes it possible to expand 
the understanding of the various patterns of convergence and divergence across Europe. It is also important to stress that the allocation of each governance case study to a particular mode is likely to be contested (one commentator's 'deliberative' mode may appear 'educational' to another). The point should be made too that different modes may be rather less distinctive in practice than they appear to be in principle. Thus, the deliberative case for 'broadening the stakeholders' can develop into an extension of older corporatist principles. These are fluid judgements, open to contestation. This suggestion is strongly supported by our empirical findings.

Based on current political and academic discussions, one of these modes was particularly important for the STAGE network - deliberative governance. As Elam and Bertilsson (2003) have argued, this mode has been the focus for theoretical and academic debates and has also received notable attention and high priority on various political agendas. In the remainder of this article, we will focus especially on processes of deliberation and engagement in relation to studies carried out in the STAGE project.

Certainly, the existence of a European rhetoric about 'science and society engagement' is an important phenomenon which has an effect in itself. What lessons can be drawn from our case studies for the conduct of future engagement initiatives?

\section{The deliberative mode in European practice}

In all the countries studied within our project, scientific governance has been on the agenda as an increasingly important aspect of policymaking. Furthermore, ideals about public participation have surfaced in all countries, although there are significant differences in the extent to which such ideals have actually been implemented, as well as in the interpretation of what engagement actually means in a specific context. Three examples of scientific governance may help to explore how the STAGE cases relate in different ways to ideals of deliberation.

The first is the Danish consensus conference on the development of electronic patient records. Here a panel of 15 citizens was asked to review and question expert knowledge with the aim of formulating a consensus statement, which was later presented to the parliament as a policy recommendation. The Danish consensus conferences are organised by the independent Danish Board of Technology and the citizens chosen have expressed interest in, but have no professional expertise and are not economically involved in, the issue at stake. As Jensen's (2004) case study demonstrates, the consensus conference can be seen as an effort to give voice to citizens in policy formulation as well as to mediate between citizens and experts in order to let citizen experiences feed into the development of the technology. There is, however, no systematic evidence for these aspirations being put into practice.

Our second case study concerns local protest based on environmental concerns in Portugal. After Portuguese authorities in 1998 decided on a small village (Souselas with 3,000 inhabitants) as the site for the co-incineration of hazardous waste in cement kilns, a protest committee was formed by a number of regional civil society organisations. Among other activities, the committee organised a number of citizen protests (including a local petition signed by more than 50,000 people) and an 'International Forum on Co-incineration' which included various specialists and experts in the search for technological alternatives. Despite the fact that there was no change in the official risk assessment of the technology and that the government displayed no faith in any form of benefits from citizen deliberation and participation, the agonistic protests did slow down the process of introducing co-incineration and after a change in government it was decided to abandon that particular process altogether.

The third example is the British 'GM Nation? Debate', which took place in the summer of 2003. After the British BSE experience, the government experienced a lack of public trust in science and the remedy was seen to be greater accountability and public participation in scientific governance. Therefore, deliberative elements were introduced into decisionmaking processes. The GM Nation? Debate was government funded, but organised by an independent steering committee. It was large scale with more than 600 local, regional and national meetings and resulted in a message of 'not yet - if ever' signalling a general public unease with GM crops. The government, however, treated the exercise as insulated from routine decision-making, and did not commit itself to incorporating any of the outcomes. In the end, it opted for a 'case by case' approach more in line with international World Trade Organization (UTO) pressures than the outcomes of the engagement exercise. 
The overall impression from all the case studies is that countries such as The Netherlands, Denmark and the UK have been relatively energetic in this regard, while deliberation has been less influential as a governance mode in Portugal, Greece and Finland. In this context, it should be acknowledged that the need for public engagement has in some cases originated within the policy establishment - as in the case with GM debate in UK and The Netherlands - or been articulated within civil society - as was demonstrated in case studies from Greece and Portugal. In order to move beyond such generalisations, we will pay particular attention in the following discussion of the various forms of implementing the ideal of participation and engagement to three issues: the purpose, the actual conduct and the outcome of deliberative engagement.

\subsection{The purpose of deliberative engagement}

One important difference between the cases is the question of whether public engagement is supposed to be an end in itself or a means to a particular outcome. The case studies demonstrate a rather diverging picture in this respect. As an end in itself public engagement seems to be introduced primarily as a way of empowering participants and creating a culture of scientific citizenship. As a means, it seems that deliberative initiatives can be employed both to extend corporativist efficiency (by resolving potential conflicts through negotiation) and to learn about consumer/citizen preferences in order to make socially robust public policy. Often there seems to be an expectation that engagement will lead to some form of consensus around controversial science and technology, but an overall conclusion from the cases is that such an expectation does not seem to be fulfilled anywhere. Engagement initiatives are by no means a quick fix to change controversy and contestation into consensus. In this context, a number of points seem relevant.

First of all, it is important to consider the relationship between engagement initiatives and the innovation agenda. In some cases, notably in Sweden and Finland, it seems that engagement with the public is primarily suggested as means to support and sustain a high rate of technical innovation (Häyrinen-Alestalo et al. 2004; Elam and Glimell 2004). The mix of corporatist and educational modes in these countries apparently makes way for expectations that engagement initiatives represent one among other ways of educating the public. This is perceived as a necessary precondition for the creation of a knowledge society in which scientific research is easily disseminated and absorbed by relevant groups of actors in society at large. In other examples, engagement initiatives are framed as a kind of counter power to the innovation agenda. This is most obvious in the case of Norway, where religious values and a sceptical public seem to be incorporated as a legitimate stakeholder in the inclusive corporativist negotiations about the future regulation and exploitation of technological possibilities (Kallerud $2004 a, b)$. A kind of middle position is demonstrated in the case of the Danish consensus conferences and the high-profile British and Dutch GM debates, which can be seen as exploring the limits of how far the innovation agenda can be pushed.

Second, it is important to be aware of the framing of scientific citizenship within the various engagement initiatives (Horst 2007; Irwin 2001). This is specifically true with regard to the role of scientific information and the perceived need for education. The Dutch nuclear energy debate is an example of a framing in which the actual debate about values and political choices was preceded by a phase in which experts from various sides were charged to collect and assess the scientific and technical evidence and come up with several energy scenarios. Participants were expected to let themselves be educated by scientific knowledge in order to be permitted entrance to the arena of discussion (Hagendijk and Terpstra 2004). Although criticism of the deficit model (e.g. Irwin 1995) has influenced later participatory designs, the question of how to balance and combine dissemination and discussion of scientific knowledge is not an easy one. There is a persisting tension regarding the question of admittance to engagement processes, demonstrated in the many procedures and arguments about who the participants of engagement exercises ideally should be. In what specific capacity do 'lay' people add to the process: is it that they are seen to have valuable knowledge that can add to the scientific knowledge or is it because they are seen to be a possible neutral judge between diverse knowledge claims? In the latter case, the issue of education becomes prominent as it seems that what is perceived as a 'neutral' citizen is often a previously 'unengaged' citizen. In these cases 'information' is regularly presented as the means to empower and engage the citizen, but this raises the controversial issue of how to choose and present the kind of information that should perform this task. 
Third, there is an interesting issue about the locus of consensus or 'rationality' in the engagement exercises. The framing very often draws upon a universal 'we' as the acting subject, yet it is very unclear how this 'we' is defined and how it will come into existence. In some of the large-scale deliberative experiments - such as the British and the Dutch GM debate - the 'we' is seen to be synonymous with the general public (Hagendijk and Egmond 2004; Healey 2004). In this case it seems that representatives of the public are asked to participate as citizens taking the perspective of the common good and considering a particular aspect of science as one, albeit a very controversial one, among many policy areas. In other cases, the 'we' seems more restricted to the actual parties included in the deliberative exercise. This is true of the Danish model of consensus conferences, where a citizens' panel is chosen to speak on its own behalf as citizens that have been presented with various and conflicting knowledge claims (Jensen 2004). In this case, the creation of the ' $w e$ ' is an outcome of the search for consensus regarding a specific scientific or technological field and it is therefore not necessarily synonymous with a more general public will.

In close connection to these points, a fourth issue is the need to consider the relationship between participatory mechanisms and political 'market research' (Irwin 2001). The cases imply that sometimes participatory methods come to be seen as - or at least criticised for being - a way of exercising consumer choice. In this context, it is necessary to discuss the difference between political consumers exercising their rights to choose based on individual preferences, and the ideal of deliberation by citizens committed to the perspective of a common good based on rational arguments. In the first form, the mode of engagement can be quite individualistic and the 'result' of an engagement process reached by aggregating individual preferences. In the second form, the mode of engagement is necessarily more social and interactive and any result can only be obtained through a joint, interactive and mutual process. Since the framing of the engagement will be shaped very differently in these two modes, confusion between them can cause considerable distress and distrust. If people are expecting to engage as citizens in a common discussion of the general development of society and technology, but find that their possible responses, by the framing of the exercise, are restricted to a display of their personal preferences and choice of, for instance, GMO products, they might get disappointed and start to think that organisers of the exercise are not really interested in deliberation. At the same time, the perceived 'value added' by an engagement initiative is very different in these modes. In the first mode the outcomes of participatory exercises might be of most value to politicians as a kind of social intelligence on public preferences, which might lead to more legitimate decisions (Horst 2003). The ideal of deliberation, however, seems to suggest additional outcomes in terms of citizen empowerment as well as an increased level of integration between science and society.

\subsection{The conduct of deliberative engagement}

It seems to be an overall lesson from various case studies that claims about procedural (un)fairness, accusations of manipulation/bias, as well as the questioning of motives, represent an important and integral part of debates over science governance. In the UK, for instance, sections of industry denounced the outcome of the GM Nation? public debate (GM Nation? 2003) by stressing that the organisation of the exercise had allowed too much space for agonistic viewpoints from radical participants rather than maintaining a more controlled deliberative process (Healey 2004). Passing judgements on forms of participation and governance is therefore a deeply embedded and significant element of the controversies. The current discussion of the actual conduct of deliberative engagement is therefore not a meta-perspective that will result in a recipe of 'successful engagement'. Rather, it is a summary of the important themes and points of conflict which have been revealed by the various case studies. Our observations cluster around three issues: the exercising body and its relation to government, the framing of the issues for deliberation, and the specific procedures followed in deliberative exercises.

Regarding the exercising body, it is important to emphasise the influence of the specific situations in which public engagement in scientific governance is introduced. Government-induced deliberative exercises present a continuum between a situation in which they are employed as a means of trying to soften or avoid agonistic stalemate in a situation of explicit controversy (as the debates about GM in The Netherlands and UK demonstrate) or as a way of dealing with anticipated, but more implicit conflicts in a governance structure which is primarily corporatist or discretionary (as we have found in Sweden and 
Finland). Meanwhile, non-governmental actors may mobilise voices of agonistic resistance and organise deliberations themselves in situations in which no active public participation is introduced by the government or attempts to do so are perceived as manipulative and one-sided. Each of these situations poses very different challenges concerning the relationship between participatory initiatives and conventional policy institutions.

In situations of civil society action, the issue is quite clearly whether, how and to what extent government will make itself sensitive to participatory engagement. As the Greek case studies demonstrate, (sporadic) action on behalf of civil society is very likely to be dismissed in order for government to continue a predominantly discretionary mode of governance (Botetzagias and Boudourides 2004). In the Portuguese waste handling case, however, it seems that nongovernmental organisation of participatory elements had an impact on government action, although the uptake was slow (Nunes and Matias 2004b).

In situations of government-induced or governmentled initiatives, the administrative question is how to situate the participatory initiatives within the existing policy-framework: should such initiatives be kept at arm's length from government or more fully integrated? The arm's length conduct of participatory initiatives is relatively common - with a semiindependent agency (e.g. the Danish Board of Technology, the Norwegian Board of Biotechnology or the UK Agriculture and Environment Biotechnology Commission) charged with conducting initiatives at a distance from government. From a governmental perspective, such a structure allows a very visible independence and autonomy for deliberative initiatives. This relationship can, however, leave the agencies in question vulnerable to political change - and might create a situation where they are seen as an optional extra to the policy process rather than a central feature.

A vital aspect of any participatory process is the actual framing of the debate, i.e. deciding which questions to ask, what sources of evidence are necessary, how the key issues are to be defined. The chosen framing is especially important when the issues dealt with can be encapsulated in a variety of ways: is the nuclear power debate in Sweden about the science and technology of radioactive waste disposal or the maintenance and encouragement of the larger nuclear fuel cycle (including military uses) (Sundqvist 2004)? Was the central question in the UK GM Nation? Debate about specific forms of GM agriculture or the future of British farming? In specific exercises, the framing of the debate frequently seems to suggest a separation of ethical, political, scientific and legal issues, but in actual deliberation these aspects are often highly intermingled. It is therefore regularly the case that the separation itself will entail implicit decisions, which prioritise certain questions over others and define the issues in particular ways.

It is also important for those sponsoring deliberative initiatives to take a broader look at the kinds of evidence that will be considered relevant and important. There is still a tendency to see public groups as contributing only to ethical and political discussions rather than having legitimate evidence and forms of knowledge to offer. Strict separations of 'public' and 'scientific' review can also mean that legitimate questions (e.g. about the need for particular innovations) do not get fully addressed.

With regard to the specific procedures followed in the deliberative exercises, they have to be seen as equitable and open. This suggests that all relevant parties have to be able to participate in procedures which are perceived to be without unfair restrictions. This, however, is clearly an ideal formulation and procedures are continuously contested in the concrete cases: which are the relevant (or 'legitimate') parties, and what should count as unfair restrictions? With regard to the relevant actors, 'exclusion by composition' (Pellizzoni, quoted in Nunes and Matias 2004a) seems to be a common theme within the case studies, although it takes different forms. In the Portuguese case study about regulation of reproductive technologies it appears as obvious that several relevant stakeholders from the public were excluded from participation by the design of the policy process (Nunes and Matias 2004a). In other cases, however, we find different ways of excluding actors. In the British and Dutch GM debates, there was an explicit wish to engage with 'neutral' citizens rather than stakeholder groups with strong viewpoints (Healey 2004; Hagendijk and Egmond 2004). It should be clear that this is also a form of exclusion by composition, since it was explicitly argued that these stakeholder groups would distort the process of public deliberation. In 
actual deliberative exercises it is probably impossible to create a design which no actor will find excluding, but the important challenge must be to be as inclusionary as possible within a given formulated purpose. The Danish consensus conferences can be seen as a good example of this as they are perceived as having a high degree of legitimacy regarding their procedures.

On a general level, there seems to be a tension between efficiency and legitimacy in the design of participatory procedures. Deliberative exercises need to be steered, but this steering can be overdone with a consequential loss of credibility. In many of our cases, considerable effort was needed to keep the initiative on-track and alive. As with the Dutch GM discussion, debates are not always successful and it would be useful to conduct further research into the circumstances surrounding success and failure. We would suggest, however, that it is not enough simply to look at the specific design of the participatory procedures. The framing of the issues and the relation between deliberative exercises and conventional policy institutions are equally important for the relative success of deliberative engagement.

\subsection{The outcome of deliberative engagement}

In general, it is difficult to identify a clear pattern of convergence with regard to the relation between policy formulation and actual participatory outcome. However, the identification of a directly causal relationship between deliberative 'output' and policy change is less straightforward than it is often presented: we are typically dealing with complex multi-variable situations where it is often hard to identify a single 'cause' of policy change. Rather, we should see the relation as one of mutual shaping and policy evolution. The central focus behind the following observations is therefore to identify and discuss possible influences on scientific governance brought about by deliberative experiments.

Despite the fact that direct influence on policy formulation is difficult to demonstrate, the cases do suggest that the introduction of deliberative engagement will have effects on scientific governance: at least, because it changes the character (and often the content) of debate and policymaking. The cases suggest that the introduction of various forms of participative exercises shape expectations towards greater inclusion of stakeholders. They also make the framing of problems as well as the organisational structure of policymaking appear as prominent issues. These changes in expectations and attentions, however, do not necessarily make policy formulation any easier - in fact quite the opposite. Deliberative engagement is therefore not a shortcut to the creation of social consensus.

We regard this observation as a central one. In many of our cases, there was quite clearly a governmental desire to achieve social consensus through deliberation with the further aim of regaining public trust. In fact, this view that greater engagement is a route to rebuilding public trust appears to be widespread across Europe. But the view that the deliberative mode can in itself (i.e. without wider institutional change) settle public concerns about the direction and form of sociotechnical change is not supported by our cases. Instead, it could be suggested that rhetorical statements about the need for deliberation which do not also consider the full institutional implications of this mode are likely to lead to alienation and increased scepticism. Stakeholders experiencing lack of support for their views have a tendency to use accusations of a hijacked debate as a means of rejecting the exercise. In this way, deliberative exercises can have the effect of making antagonisms even more pronounced (which can be considered as both a negative and a positive impact).

In all circumstances, the case studies suggest that deliberation can be as much a source of conflict as a means to reach a solution. How should we interpret this? It might be concluded from the above that the ideal of deliberation is too contested, contextually sensitive and flexible to be of any intellectual or policy value. Certainly, our cases have identified:

- A partiality within the conduct of deliberation across Europe: only particular (generally high profile) issues have been selected for deliberative discussion, but in the overall picture, these initiatives tend to be rather small-scale and marginal.

- A conflictuality within the cases: despite the enthusiasm among government bodies for deliberation as a means of consensus generation, we find considerable areas of dissent and disagreement in each of the specific contexts also after the deliberative exercises took place.

- A fragility to these initiatives: deliberative processes have not become embedded in 
government but often appear to be at the point of termination. For example, both the Danish Board of Technology and the UK Agriculture and Environment Biotechnology Commission have been under threat at different points during our project (with the latter ultimately being disbanded in 2005).

The interpretation of these points as a defeat for deliberative ideals, however, depends on the relative weight placed on consensus and institutionalisation. We propose that neither of them should be regarded as crucial for the deliberative agenda. Consensus may not necessarily be a desirable (let alone achievable) policy objective. And institutionalisation of a deliberative agenda might render the process bureaucratic and instrumental, thereby removing the political vitality from the initiatives. Rather than viewing these three characteristics as flaws (or as problems to be solved), they could be perceived as necessary incoherences and loci of vitality in the deliberative experiments. Following this argument, the antagonistic elements, the confusion between the different modes and the constant threat of collapse represent a central part of keeping participatory exercises alive. These challenges might be the very same characteristics that give participatory exercises their capacity to invoke (and provoke) change - although the promises of deliberation might never be fulfilled as such. These partial, conflictual and fragile tendencies however, need to be balanced with a policyframework which is open to the issues raised, flexible in the face of competing assessments, and committed to taking the outcomes of deliberative exercises seriously.

Our general argument is that there is a distinct character - or at least common characteristics - to current European debates over scientific governance, and the infusion of deliberative ideals is a central part of this character. This conclusion, of course, does not suggest that this character is only a European phenomenon. At a specific level, each of the cases and indeed each of the nations studied - has its own distinctiveness. We are not trying to blur or deny significant differences between the countries and contexts under discussion here. Instead, our argument is that Europe represents a characteristic fusion (or, more accurately, uneasy mix) of governance styles.

\section{European scientific governance in a global context}

The STAGE project was very much a European study - and one based on 'only' eight countries, with a particular emphasis on richer Western nations rather than the new accession countries of the East. Despite this, strong patterns of diversity as well as congruence were identified. Our empirical experience was certainly not of a homogeneous bloc, but rather of a dynamic and contested range of discussions with some common themes as discussed above. While certain forms of political and development theory speak in sweeping generalisations of globalisation, knowledge societies and the developed/developing worlds, our experience was of shifting contextualities, competing agenda and changing political cultures. Denmark - often presented internationally as the home of consensus formation and societal inclusion - has more recently become the locus for worldwide and divisive debates over immigration, cultural difference and the nature of free speech. Finland meanwhile has been undergoing tremendous economic and industrial change as it emerges as a global centre of technological innovation and development. Of course, governments change and political cultures have deeper roots, but we were constantly reminded of the dangers of drawing easy conclusions about national and international experience - and in particular of pinning down national systems of governance to unitary categorisation (a tendency to which cross-European studies are particularly drawn).

Our typology of styles of governance and public engagement allowed us to explore differences as well as points of convergence and its application documented that it would be a misguided simplification to speak of a new European approach in the singular, despite signs of convergence, mutual learning and mimicking. Going further, it would be interesting to see whether experiences with public engagement in other parts of the world can be made sense of using this heuristic scheme. What in turn would this imply for more general debates about politics, science and democratic theory? As has already been suggested (Gaventa 2006), debates about deepening democracy seem to vary around the world depending upon the specific political and socioeconomic conditions and experiences. Does this also hold for public engagement with science and technology in such diverse contexts? 
As pointed out above, the deliberative mode is of special importance in the STAGE project as well as in European debates about scientific and technological innovation. On the basis of our work, we conclude that it is important not to be taken in too easily by the almost universal endorsement of public participation and deliberation. Such terms mean different things to different people. As we hope to have shown, various aims may be associated with public participation and deliberation. The issues may be framed quite differently with very different agenda. The design and actual running of exercises can also vary substantially. In this respect, it is important not to dismiss conflicts and debates about the genuine or manipulative character of specific initiatives as disrupting the debate about the 'real' questions. Such diversions should be seen as part and parcel of the processes in which we are interested.

Over the last couple of years, there have been quite a number of exercises to identify best practices in public engagement and various recipe books and reports have been published. Such attempts are no doubt helpful but on the basis of our work we conclude that they will remain limited as they are unavoidably overfocused on procedural issues and characteristically ignore two key issues. First, such attempts tend to ignore how the fate of initiatives depends on the contested framings of the issues at stake by real and envisaged participants. Second, their relation to and embedding in established form of politics and policymaking in the respective country is crucial for their effectiveness. Looking back at the European experience so far, the partiality, conflictuality, and fragility of attempts to democratise innovation and technological change stand in disconcerting relation to the almost universal endorsement of deliberative ideals at the ideological level.

Speculating more widely beyond our cases, a number of further issues seem relevant from a global perspective. In the first place, systems of scientific governance both reflect wider political cultures (a point we have already emphasised) but also represent important forms of nation-building and repositioning. This is especially clear within the European rhetoric of the Lisbon agenda which, while clearly prioritising the familiar economic objectives of competitiveness, productivity and growth also incorporates social objectives such as the quality of life and of jobs, sustainability and social cohesion. These broader repositionings, however rhetorical, are at least a reference point for the more detailed politics of individual exercises of public participation. Furthermore, they can be seen to carry through into the international policy of European states. Thus, during his period of office, Tony Blair's domestic vision of a successful Britain was tied up both with internationally competitive, science-led progress but also the need to gain public support and trust. In parallel, the UK Department for International Development policy (DFID 2005) emphasised the importance of research on governance in relation to development, and supported continuing research 'on how citizens can develop the ability to participate... and how [they] can hold states accountable ....

As the previously considered 'developing' nations (Payne 2005) move forward with their own visions of science-led social change, it will be important to consider the systems of governance, and the scope and mechanisms of participation and accountability in particular, which emerge alongside and underpin these visions. Taking this further, it will be an important issue of how the agenda of innovation, democratisation and accountability develop and intervene within each other. Participation may lift up situated knowledge and give it a voice in the political process, as Cozzens et al. have pointed out (2007). Yet, situations of antagonism between these agendas are also certainly possible, accentuating the boundary between deliberative, corporatist and agonistic forms of development and governance. Mutual invigoration (e.g. through such concepts as 'user-driven innovation') is perhaps the best outcome one may expect.

Second, discussions over scientific governance within Europe seem especially important to broader debates over the relationship between science, technology and democracy. While experience so far of engagement is certainly open to criticism as being 'something of a mirage' (Wynne 2005: 68), this conclusion should not conceal the questions and challenges which are actively at play within apparently modest 'social experiments'. Among these, we would identify: the relationship between societal assessments and the innovation process, the most appropriate forms of 'democratisation' for particular contexts (one size indeed does not fit all), the relationship between local initiatives and national/international political systems, and competing models of citizenship. Going further, we would suggest that experience in this area raises questions also of the responsiveness and accountability of scientific institutions to wider society. This is not 
simply a question of encouraging greater institutional openness but also of addressing the very frameworks in which issues are currently being framed and presented to the wider publics.

Third, and very importantly, the emphasis in this article has implicitly been on what the rest of the world can learn from European experience - an emphasis put forward with appropriate empirical humility but which is nevertheless undeniable. Discussion of 'Europe in a global context' must also consider how the nations of Europe can benefit

\section{Note}

* The authors would like to thank colleagues in the STAGE network as well as the EU Commission for financial support to the STAGE network (contract no. HPSE-CT2001-50003).

Corresponding author: Maja Horst, Department of Management, Politics and Philosophy,

\section{References}

Bertilsson, Margareta (2004) Governance of Science and Technology: The Case of Denmark, STAGE Discussion Paper 31, Copenhagen: University of Copenhagen

Blok, A. (2007) 'Experts on Public Trial: On Democratizing Expertise through a Danish Consensus Conference', Public Understanding of Science 16.2: 163-82

Botetzagias, I. and Boudourides, M.A. (2004) Environmental Organisations in Greece, STAGE Discussion Paper 8, Patras: University of Patras

Botetzagias, losif A.; Boudourides, Moses A. and Kalamaras, Dimitris B. (2004a) ICTs in Greece, STAGE Discussion Paper 18, University of Patras

Botetzagias, losif A.; Boudourides, Moses A. and Kalamaras, Dimitris B. (2004b) Biotechnology in Greece, STAGE Discussion Paper 10, University of Patras

Commission of the European Communities (CEC) (2002) Science and Society: Action Plan, Brussels: European Communities

Cozzens, S.; Hagendijk, R.; Healey, P. and Santos Pereira, T. (2007) A Framework for Analyzing Science, Technology and Inequalities: Preliminary Observations, James Martin Institute Working Paper 3, Oxford: James Martin Institute, University of Oxford

Department for International Development (DFID) (2005) DFID Research Funding Framework 2005-2007, www.dfid.gov.uk/pubs/files/ from international experience and draw from other cultural and political traditions. This point is made all the more important by the recent expansion of the EU to include nations with very diverse economic and political foundations. Certainly, the notion that the richer countries of Europe represent an appropriate example in this area, is open to substantial dispute. At a time when the old categorisations of the 'developed' and 'developing' worlds are collapsing, the nations of Europe must look outside as well as inside their boundaries for democratic imagination and societal reappraisal.

Copenhagen Business School, Porcelaenshaven 18A, DK-2000 Frederiksberg C, Denmark, mh.lpf@cbs.dk.

1 All STAGE Discussion Papers are available at: www.stage-research.net

researchframework/research-framework-2005.pdf (accessed 3 July 2007)

Elam, Mark (2004) Democracy at Stake: Film, Folkbildning and Public Engagement With Biotechnology in Sweden, STAGE Discussion Paper 24, Gothenburg: Gothenburg University

Elam, M. and Bertilsson, M. (2003) 'Consuming, Engaging and Confronting Science: The Emerging Dimensions of Scientific Citizenship', European Journal of Social Theory 6.2: 233-51

Elam, M. and Glimell, H. (2004) Knowledge Society as the Republic of Science Enlarged: The Case of Sweden, STAGE Discussion Paper 26, Gothenburg: Gothenburg University

Gaventa, J. (2006) Triumph, Deficit or Contestation: Deepening the 'Deepening Democracy' Debate, IDS Working Paper 264, Brighton: IDS

GM Nation? (2003) The Findings of the Public Debate, www.gmnation.org.uk (accessed 3 July 2007)

Glimell, Hans (2004) Restored Scientific Authority and Orchestrated Deliberation: A Review of the Current Swedish S\&T Policies, STAGE Discussion Paper 27, Gothenburg: Gothenburg University

Hagendijk, R.P. (2004) 'The Public Understanding of Science and Public Participation in Regulated Worlds', Minerva 42: 41-59

Hagendijk, R.P. and Egmond, M. (2004) The GM Food Debate in The Netherlands: 1999-2002, STAGE Discussion Paper 14, Amsterdam: University of Amsterdam

Hagendijk, R.P. and Irwin, A. (2006) 'Public 
Deliberation and Governance: Engaging with Science and Technology in Contemporary Europe', Minerva 44.2: 167-84

Hagendijk, R.P. and Kallerud, E. (2003) Changing Conceptions and Practices of Governance in Science and Technology in Europe: A Framework for Analysis, STAGE Discussion Paper 2, Amsterdam: University of Amsterdam

Hagendijk, R.P. and Terpstra, A. (2004) Technology, Risk and Democracy: The Dutch Nuclear Energy Debate (1981-1984), STAGE Discussion Paper 12, Amsterdam: University of Amsterdam

Hagendijk, R.P.; Healey, P.; Horst, M. and Irwin, A. (2005) Science, Technology and Governance in Europe, final report on the STAGE project

Häyrinen-Alestalo, M.; Pelkonen, A. and Snell, K. (2004) New Technologies Challenging Old Structures of Governance, STAGE Discussion Paper 7, Helsinki: University of Helsinki

Häyrinen-Alestalo, Marja and Snell, Karoliina (2004) Market Orientations and Mediation of Public Opinions in Finnish Biotechnology, STAGE Discussion Paper 6, Helsinki: University of Helsinki Healey, P. (2004) The 2003 UK GM Crops Debate, STAGE Discussion Paper 28, Oxford: James Martin Institute, University of Oxford

Horst, M. (2007) 'Public Expectations of Gene Therapy: Scientific Futures and the Performative Effects on Scientific Citizenship', Science, Technology and Human Values 32.2: 150-71

Horst, M. (2005) 'Cloning Sensations: Mass Mediated Articulation of Social Responses to Controversial Biotechnology', Public Understanding of Science 14: 185-200

Horst, M. (2003) 'Controversy and Collectivity: Articulations of Social and Natural Order in Mass Mediated Representations of Biotechnology', doctoral thesis, Copenhagen Business School, Denmark

Irwin, A. (2006) 'The Politics of Talk: Coming to Terms with the 'New' Scientific Governance', Social Studies of Science 36.2: 299-320

Irwin, A. (2001) 'Constructing the Scientific Citizen: Science and Democracy in the Biosciences', Public Understanding of Science 10.1: 1-18

Irwin, A. (1995) Citizen Science, London: Routledge Jasanoff, S. (2005) Designs on Nature, Princeton: Princeton University Press

Jensen, C.B. (2004) Citizen Projects and Consensus Building at the Danish Board of Technology: On Experiments in Democracy, STAGE Discussion Paper 4, Aarhus: Aarhus University
Kallerud, E. (2004a) Controversy Over Institutional Structure and Design in Norwegian Governance of Science and Technology, STAGE Discussion Paper 16, Oslo: NIFU STEP

Kallerud, E. (2004b) Science, Technology and Governance in Norway, STAGE Discussion Paper 19, Oslo: NIFU STEP

Lassen, Jesper (2004) Changing Modes of Biotechnology Governance in Denmark, STAGE Discussion Paper 3, Copenhagen: Royal Veterinary and Agricultural University

Nunes, J.A. and Matias, M. (2004a) A Regulatory Void? Reprogenetics in Portugal, STAGE Discussion Paper 20, Coimbra: University of Coimbra

Nunes, J.A. and Matias, M. (2004b) Agonistic Spaces, Consensus Politics and the Trials of Governance: Environmental Policies and Conflict in Portugal, STAGE Discussion Paper 21, Coimbra: University of Coimbra

Nunes, J.A and Matias, M. (2004) Science, Technology and Governance in Portugal, STAGE Discussion Paper 22, Coimbra: University of Coimbra

Nunes, J.A.; Pereira, T.S. and Matias, M. (2004) The BSE Crisis in Portugal or How to 'Domesticate' European Regulatory Policies, STAGE Discussion Paper 23, Coimbra: University of Coimbra Payne, A. (2005) The Global Politics of Unequal Development, Basingstoke: Palgrave Macmillan

Pelkonen, Antti (2004) Questioning the Finnish Model - Forms of Public Engagement in Building the Finnish Information Society, STAGE Discussion Paper 5, Helsinki: University of Helsinki

Rothstein, H.; Irwin, A.; Yearley, S. and McCarthy, E. (1999) 'Regulatory Science, Europeanisation and the Control of Agrochemicals', Science, Technology and Human Values 24.2: 241-64

Stilgoe, J.; Irwin, A. and Jones, K. (2006) The Received Wisdom: Opening Up Expert Advice, London: Demos

Sundqvist, G. (2004) Constrained Deliberation: Public Involvement in Swedish Nuclear Waste Management, STAGE Discussion Paper 25, Gothenburg: Gothenburg University

Wouters, Paul (2004) 'It Can't be Uninvented' - The Dutch Debate About the Chip in the Early 1980s, STAGE Discussion Paper 13, Amsterdam: Royal Netherlands Academy of Arts and Sciences

Wynne, B. (2005) 'Risk as Globalizing Discourse? Framing Subjects and Citizens', in M. Leach, I. Scoones and B. Wynne (eds) Science and Citizens: Globalization and the Challenge of Engagement, London: Zed Books 